\title{
Stochastic Modelling of a Computer System with Hardware Redundancy
}

\author{
S.C. Malik \\ Dept. of Statistics \\ M.D. University, Rohtak-124001 (India)
}

\author{
V.J. Munday \\ Dept. of Statistics \\ M.D. University, Rohtak-124001 (India)
}

\begin{abstract}
In this paper, an effort for the stochastic analysis of a computer system has been made considering the idea of hardware redundancy in cold standby. The hardware and software failures occur independently in the computer system with some probability. A single server is employed immediately to conduct hardware repair and software upgradation on need basis. The repair and up-gradation activities performed by the server are perfect. The time to hardware and software failures follows negative exponential distribution, whereas the distributions of hardware repair and software upgradation times are taken as arbitrary with different probability density functions. The expressions for various reliability measures are derived in steady state using semiMarkov process and regenerative point technique. The graphs are drawn for arbitrary values of the parameters to depict the behaviour of some important performance measures of the system model.
\end{abstract}

\section{Keywords}

Computer System, Hardware Redundancy, Stochastic Model and Reliability Measures

\section{INTRODUCTION}

The demand for computer systems has increased many folds during last few years because of their wide applications in several sensitive areas like banking, communication, home appliances, automobiles and aerospace. Consequently, this leads to the need to specify and design computing systems which could fulfil the requirements of targeted applications at the lowest cost. But, designing a system to perform its intended job at least for a specific duration always has been a challenge to the reliability practitioners. The technique of redundancy has been adopted frequently as an effective strategy for enhancing system life span. Cao and Wu [1989], Lam [1997], Yadavalli et al. [2004] and Kumar et al. [2012] analyzed repairable system models using unit wise redundancy.

In spite of increasing demand of computer technology, a little work has been dedicated to the stochastic modelling of computer systems with independent failures of hardware and software components. And, most of the research work has been carried out either considering hardware or software alone. However, Malik and Anand [2010, 12] and Kumar et al. [2013] tried to establish computer system models with unit wise cold standby redundancy. It has been proved that component wise redundancy is better than unit wise redundancy in sense of reliability.

Thus, purpose of the present study is to analyze stochastically a computer system by providing hardware redundancy in cold standby. In computer system, hardware and software failures occur independently with some probability. A single server is called immediately to conduct hardware repair and software up-gradation when needed. The repair and up-gradation activities performed by the server are perfect. The time to hardware and software failures follows negative exponential distribution while the distributions of hardware repair and software up-gradation times are taken as arbitrary with different probability density functions. The expressions for various reliability measures such as transition probabilities and mean sojourn times, mean time to system failure (MTSF), availability, busy period of the server due to hardware repair and software up-gradation, expected number of hardware repairs and software up-gradations and profit function are derived in steady state using semi-Markov process and regenerative point technique. The cost-benefit analysis has been made using these measures. The graphs are drawn for arbitrary values of the parameters to depict the behaviour of MTSF, availability and profit function of the system model.

\section{NOTATIONS}

\begin{tabular}{|c|c|}
\hline & \\
\hline$\underline{E}$ & : Set of regenerative states \\
\hline $\bar{E}$ & : Set of non-regenerative states \\
\hline $\mathrm{O}$ & : Computer system is operative \\
\hline Hes & : Hardware is in cold standby \\
\hline $\mathrm{a} / \mathrm{b}$ & $\begin{array}{l}\text { : Probability that the system has } \\
\text { hardware / software failure }\end{array}$ \\
\hline$\lambda_{1} / \lambda_{2}$ & : Hardware/Software failure rate \\
\hline $\mathrm{HFUr} / \mathrm{HFWr}$ & $\begin{array}{l}\text { The hardware is failed and under } \\
\text { repair/waiting for repair }\end{array}$ \\
\hline SFUg/SFWUg & $\begin{array}{l}\text { : The software is failed and under/waiting } \\
\text { up- gradation }\end{array}$ \\
\hline HFUR/HFWR & $\begin{array}{l}\text { The hardware failed and } \\
\text { continuously under repair / } \\
\text { waiting for repair from previous } \\
\text { state }\end{array}$ \\
\hline SFUG/SFWUG & $\begin{array}{l}\text { The software is failed and } \\
\text { continuously under up-gradation } \\
\text { /waiting for up- gradation from } \\
\text { previous state }\end{array}$ \\
\hline $\mathrm{g}(\mathrm{t}) / \mathrm{G}(\mathrm{t})$ & : pdf/cdf of hardware repair time \\
\hline $\mathrm{f}(\mathrm{t}) / \mathrm{F}(\mathrm{t})$ & $\begin{array}{l}\text { : pdf/cdf of software up-gradation } \\
\text { time }\end{array}$ \\
\hline $\mathrm{q}_{\mathrm{ij}}(\mathrm{t}) / \mathrm{Q}_{\mathrm{ij}}(\mathrm{t})$ & $\begin{array}{l}: \text { pdf / cdf of first passage time } \\
\text { from regenerative state } S i \text { to a } \\
\text { regenerative state } S \mathrm{j} \text { or to a } \\
\text { failed state } S j \text { without visiting } \\
\text { any other regenerative state in } \\
(0, \mathrm{t}]\end{array}$ \\
\hline $\mathrm{q}_{\mathrm{ij.k}}(\mathrm{t}) / \mathrm{Q}_{\mathrm{ij.k}}(\mathrm{t})$ & $\begin{array}{l}\text { : pdf/cdf of direct transition time } \\
\text { from regenerative state } S i \text { to a } \\
\text { regenerative state } S j \text { or to a failed } \\
\text { state } S j \text { visiting state } S_{k} \text { once in } \\
(0, t]\end{array}$ \\
\hline $\mathrm{M}_{\mathrm{i}}(\mathrm{t})$ & $\begin{array}{l}\text { Probability that the system up } \\
\text { initially in state } S_{i} \in E \text { is up at } \\
\text { time } t \text { without visiting to any } \\
\text { regenerative state }\end{array}$ \\
\hline
\end{tabular}




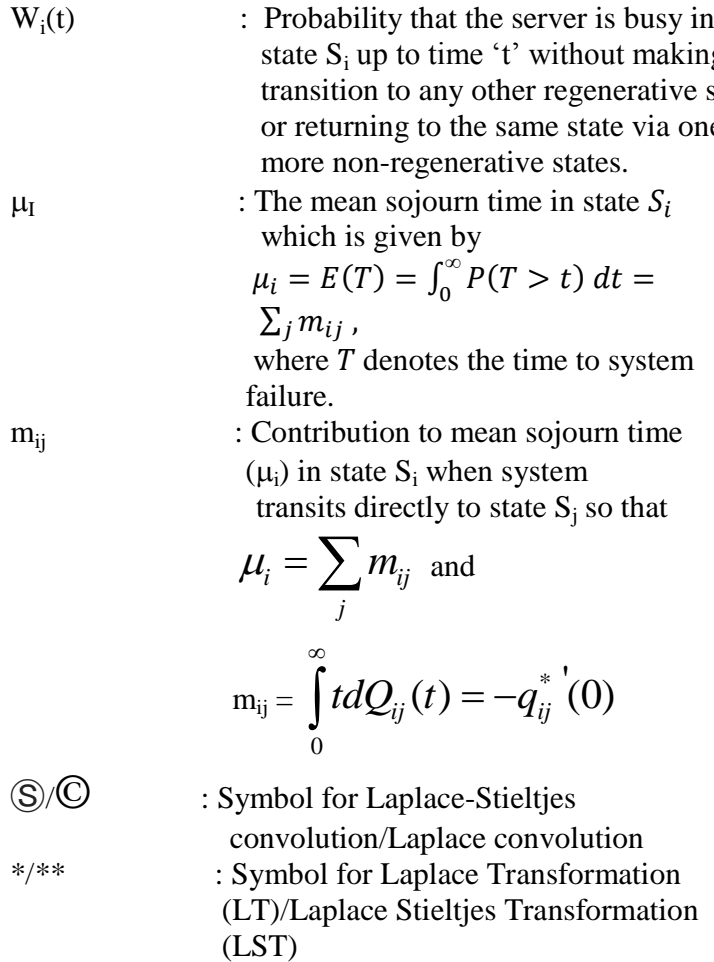

\section{TRANSITION PROBABILITIES AND MEAN SOJOURN TIMES}

Simple probabilistic considerations yield the following expressions for the non-zero elements.

$p_{i j}=Q_{i j}(\infty)=\int_{0}^{\infty} q_{i j}(t) d t$
$p_{01}=\frac{a \lambda_{1}}{a \lambda_{1}+b \lambda_{2}}, \quad p_{02}=\frac{b \lambda_{2}}{a \lambda_{1}+b \lambda_{2}}$,
$p_{10}=g^{*}\left(a \lambda_{1}+b \lambda_{2}\right)$
$p_{13}=\frac{b \lambda_{2}}{a \lambda_{1}+b \lambda_{2}}\left\{1-g^{*}\left(a \lambda_{1}+b \lambda_{2}\right)\right\}$
$p_{14}=\frac{a \lambda_{1}}{a \lambda_{1}+b \lambda_{2}}\left\{1-g^{*}\left(b a \lambda_{1}+b \lambda_{2}\right)\right\}$,
$p_{20}=f^{*}(0), p_{32}=p_{41}=g^{*}(0)$

For $\mathrm{f}(\mathrm{t})=\theta e^{-\theta t}$ and $\mathrm{g}(\mathrm{t})=\alpha e^{-\alpha t}$ we have

$p_{11.4}=\frac{a \lambda_{1}}{a \lambda_{1}+b \lambda_{2}}\left\{1-g^{*}\left(a \lambda_{1}+b \lambda_{2}\right)\right\} p_{12.3}=\frac{b \lambda_{2}}{a \lambda_{1}+b \lambda_{2}}\{1-$ $\left.g^{*}\left(a \lambda_{1}+b \lambda_{2}\right)\right\}$

But, $\mathrm{h}^{*}(0)=\mathrm{f}^{*}(0)=\mathrm{g}^{*}(0)=1$ and $\mathrm{a}+\mathrm{b}=1$

It can be easily verified that

$\mathrm{p}_{01}+\mathrm{p}_{02}=\mathrm{p}_{10}+\mathrm{p}_{13}+\mathrm{p}_{14}=\mathrm{p}_{20}=\mathrm{p}_{32}=\mathrm{p}_{41}=\mathrm{p}_{10}+\mathrm{p}_{11.4}+\mathrm{p}_{12.3}=1$

(2)

The mean sojourn times $\left(\mu_{i}\right)$ is the state $S_{i}$ are

$$
\begin{aligned}
& \mu_{0}=\frac{1}{a \lambda_{1}+b \lambda_{2}} \\
& \mu_{1}=\left\{\frac{1}{a \lambda_{1}+b \lambda_{2}}\right\}\left\{1-g^{*}\left(a \lambda_{1}+b \lambda_{2}\right)\right\}=\frac{1}{a \lambda_{1}+b \lambda_{2}+\alpha} \\
& \mu_{2}=\frac{1}{\theta} \\
& \text { Also } \\
& \mu_{0}=m_{01}+m_{02}, \\
& \mu_{1}=m_{10}+m_{13}+m_{14}, \quad \mu_{2}=m_{20} \\
& \text { and } \\
& \mu_{1}^{\prime}=m_{10}+m_{11.4}+m_{12.3}=\frac{1}{\alpha}
\end{aligned}
$$

\section{RELIABILITY AND MEAN TIME TO SYSTEM FAILURE (MTSF)}

Let $\phi_{i}(t)$ be the cdf of first passage time from regenerative state $S_{i}$ to a failed state. Regarding the failed state as absorbing state, we have the following recursive relations for $\phi_{i}(t)$ :
$\phi_{0}(\mathrm{t})=\mathrm{Q}_{01}(\mathrm{t}) \mathrm{S} \phi_{1}(\mathrm{t})+\mathrm{Q}_{02}(\mathrm{t})$

$\phi_{1}(\mathrm{t})=\mathrm{Q}_{10}(\mathrm{t}) S \phi_{0}(\mathrm{t})+\mathrm{Q}_{13}(\mathrm{t})+\mathrm{Q}_{14}(\mathrm{t})$

Taking LST of equation (4) and solving for $\phi^{* *}{ }_{0}(\mathrm{~s})$,

We have

$\mathrm{R}^{*}(\mathrm{~s})=\frac{1-\phi_{0}^{* *}(s)}{s}$

The reliability of the system model can be obtained by taking Laplace inverse transform of the equation (5).

The mean time to system failure (MTSF) is given by

$\mathrm{MTSF}=\lim _{s \rightarrow 0} \frac{1-\phi_{0}^{* *}(s)}{s}=\frac{N_{1}}{D_{1}}$

Where

$\mathrm{N}_{1}=\mathrm{p}_{01} \mu_{1}+\mu_{0}$ and $\mathrm{D}_{1}=1-\mathrm{p}_{01} \mathrm{p}_{10}$

\section{STEADY STATE AVAILABILITY}

Let $A_{i}(t)$ be the probability that the system is in up-state at instant' $t$ ' given that the system entered regenerative state $S_{i}$ at $t=0$. The recursive relations for $A_{i}(t)$ are given as:

$\mathrm{A}_{0}(\mathrm{t})=\mathrm{M}_{0}(\mathrm{t})+\mathrm{q}_{01}(\mathrm{t}) \odot \mathrm{A}_{1}(\mathrm{t})+\mathrm{q}_{02}(\mathrm{t}) \odot \mathrm{A}_{2}(\mathrm{t})$

$\mathrm{A}_{1}(\mathrm{t})=\mathrm{M}_{1}(\mathrm{t})+\mathrm{q}_{10}(\mathrm{t}) \odot \mathrm{A}_{0}(\mathrm{t})+\mathrm{q}_{11.4}(\mathrm{t}) \odot \mathrm{A}_{1}(\mathrm{t})+\mathrm{q}_{12.3}(\mathrm{t})(C$

$\mathrm{A}_{2}(\mathrm{t})$

$\mathrm{A}_{2}(\mathrm{t})=\mathrm{q}_{20}(\mathrm{t}) \odot \mathrm{A}_{0}(\mathrm{t})$

where

$\mathrm{M}_{0}(\mathrm{t})=e^{-\left(a \lambda_{1}+b \lambda_{2}\right) t}, \quad \mathrm{M}_{1}(\mathrm{t})=e^{\left(a \lambda_{1}+b \lambda_{2}\right) t} \overline{G(t)}$

Taking LT of equation (8) and solving for $A_{0}^{*}(s)$, the steady state availability is given by

$$
A_{0}(\infty)=\lim _{s \rightarrow 0} s A_{0}^{*}(s)=\frac{N_{2}}{D_{2}}
$$

Where

$$
\begin{aligned}
N_{2}=\mu_{0}\left(1-\mathrm{p}_{11.4}\right)+\mathrm{p}_{01} \mu_{1} \\
\quad D_{2}= \\
\quad\left(1-p_{11.4}\right) \mu_{0}+p_{10} \mu_{1}^{\prime}+p_{10} p_{02} \mu_{2}+\quad p_{12.3} \mu_{0} \mu_{2}
\end{aligned}
$$

\section{BUSY PERIOD OF THE SERVER}

(a). Due to Hardware Repair

Let $B_{i}^{H}(t)$ be the probability that the server is busy in repairing the unit due to hardware failure at an instant ' $t$ ' given that the system entered state $S_{i}$ at $t=0$. The recursive relations for $B_{i}^{H}(t)$ are as follows:

$$
\begin{aligned}
& B_{0}^{H}(\mathrm{t})=\mathrm{q}_{01}(\mathrm{t}) \odot B_{1}^{H}(\mathrm{t})+\mathrm{q}_{02}(\mathrm{t}) \odot B_{2}^{H}(\mathrm{t}) \\
& B_{1}^{H}(\mathrm{t})=W_{1}^{H}(t)+\mathrm{q}_{10}(\mathrm{t}) \odot B_{0}^{H}(\mathrm{t})+\mathrm{q}_{11.4}(\mathrm{t}) \odot B_{1}^{H}(\mathrm{t})+ \\
& \mathrm{q}_{12.3}(\mathrm{t}) \odot B_{2}^{H}(\mathrm{t}) \\
& B_{2}^{H}(\mathrm{t})=\mathrm{q}_{20}(\mathrm{t}) \odot B_{0}^{H}(\mathrm{t}) \\
& \text { where } \\
& \qquad W_{1}^{H}(t)=e^{\left(a \lambda_{1}+b \lambda_{2}\right) t} \overline{G(t)}+\left(a \lambda_{1} e^{\left(a \lambda_{1}+b \lambda_{2}\right) t}(\mathrm{C} 1)\right. \\
& G(t)+\left(b \lambda_{2} e^{\left(a \lambda_{1}+b \lambda_{2}\right) t}(\mathrm{C} 1) \overline{G(t)}\right.
\end{aligned}
$$

\section{(b). Due to Software Up-Gradation}

Let $B_{i}^{S}$ (t)be the probability that the server is busy due to replacement of the software at an instant ' $t$ ' given that the system entered the regenerative state $S_{i}$ at $t=0$. We have the following recursive relations for $B_{i}^{S}(\mathrm{t})$ :

$$
\begin{aligned}
B_{0}^{S}(\mathrm{t})= & \mathrm{q}_{01}(\mathrm{t}) \odot B_{1}^{S}(\mathrm{t})+\mathrm{q}_{02}(\mathrm{t}) \odot B_{2}^{S}(\mathrm{t}) \\
B_{1}^{S}(\mathrm{t})= & \mathrm{q}_{10}(\mathrm{t}) \odot B_{0}^{S}(\mathrm{t})+\mathrm{q}_{11.4}(\mathrm{t}) \odot B_{1}^{S}(\mathrm{t})+ \\
& \mathrm{q}_{12.3}(\mathrm{t}) \odot B_{2}^{S}(t)
\end{aligned}
$$


$B_{2}^{S}(\mathrm{t})=W_{2}^{S}(t)+\mathrm{q}_{20}(\mathrm{t}) \odot B_{0}^{S}(\mathrm{t})$

where

$W_{2}^{S}(t)=\overline{F(t)} d t$

Taking LT of equations (11) \& (12), solving for $B_{0}^{*^{H}}$ (s) and $B_{0}^{*^{s}}$ (s), the time for which server is busy due to repair and replacements respectively is given by

$$
B_{0}^{H}=\lim _{s \rightarrow 0} s B_{0}^{H^{*}}(s)=\frac{N_{3}^{H}}{D_{2}}
$$

$$
B_{0}^{S}=\lim _{s \rightarrow 0} s B_{0}^{S^{*}}(s)=\frac{N_{3}^{S}}{D_{2}}
$$

(14)

where

$N_{3}^{H}=p_{01} W_{1}^{H *}(0)$

$N_{3}^{S}=\left\{p_{01} p_{12.3}+p_{02}\left(1-p_{11.4}\right)\right\} W_{2}^{S *}(0)$

and $\mathrm{D}_{2}$ is already mentioned.

\section{EXPECTED NUMBER OF HARDWARE REPAIRS}

Let $N H R_{i}(t)$ be the expected number of hardware repairs by the server in $(0, t)$ given that the system entered the regenerative state $S_{\mathrm{i}}$ at $\mathrm{t}=0$. The recursive relations for

$\operatorname{NHR}_{i}(t)$ are given as:

$\mathrm{NHR}_{0}(\mathrm{t})=\mathrm{Q}_{01}(\mathrm{t})\left(\mathrm{s}\left[1+\mathrm{NHR}_{1}(\mathrm{t})\right]+\mathrm{Q}_{02}(\mathrm{t})(\mathrm{S}) \mathrm{NHR}_{2}(\mathrm{t})\right.$

$\mathrm{NHR}_{1}(\mathrm{t})=\mathrm{Q}_{10}(\mathrm{t})\left(S \mathrm{NHR}_{0}(\mathrm{t})+\mathrm{Q}_{11.4}(\mathrm{t})\left(S \mathrm{NHR}_{1}(\mathrm{t})+\mathrm{Q}_{12.3}\right.\right.$

(t) $\left(5 \mathrm{NHR}_{2}(\mathrm{t})\right.$

$\mathrm{NHR}_{2}(\mathrm{t})=\mathrm{Q}_{20}(\mathrm{t})$ (S)NHR $0(\mathrm{t})$

Taking LST of equation (16) and solving for $R_{0}^{* *}(s)$. The expected number of hardware repair is given by

$\mathrm{NHR}_{0}=\lim _{s \rightarrow 0} s N H R_{0}^{* *}(s)=\frac{N_{4}}{D_{2}}$

where

$\mathrm{N}_{4}=\mathrm{p}_{01}\left(1-\mathrm{p}_{11.4}\right)$

and $\mathrm{D}_{2}$ is already mentioned.

\section{EXPECTED NUMBER OF}

\section{SOFTWARE UP-GRADATIONS}

Let $\mathrm{NSU}_{\mathrm{i}}(\mathrm{t})$ be the expected number of software upgradations in $(0, t]$ given that the system entered the regenerative state $S_{i}$ at $t=0$. The recursive relations for $\mathrm{NSU}_{\mathrm{i}}(\mathrm{t})$ are given as follows

$$
\begin{aligned}
\mathrm{NSU}_{0}(\mathrm{t})= & \mathrm{Q}_{01}(\mathrm{t}) \text { (S) } \mathrm{NSU}_{1}(\mathrm{t})+\mathrm{Q}_{02}(\mathrm{t}) \text { (s) } \\
& {\left[1+\mathrm{NSU}_{2}(\mathrm{t})\right] } \\
\mathrm{NSU}_{1}(\mathrm{t})= & \mathrm{Q}_{10}(\mathrm{t}) \text { (S) } \mathrm{NSU}_{0}(\mathrm{t})+\mathrm{Q}_{11.4}(\mathrm{t}) \text { (S) } \mathrm{NSU}_{1}(\mathrm{t}) \\
& +\mathrm{Q}_{12.3}(\mathrm{t}) \text { (S) } \mathrm{NSU}_{2}(\mathrm{t}) \\
\mathrm{NSU}_{2}(\mathrm{t})= & \mathrm{Q}_{20}(\mathrm{t}) \text { (S) } \mathrm{NSU}_{0}(\mathrm{t})
\end{aligned}
$$

Taking LST of equation (19) and solving for $N_{0}^{* *}(s)$. The expected numbers of software up-gradation are given by

$N S U_{0}(\infty)=\lim _{s \rightarrow 0} s N S U_{0}^{* *}(s)=\frac{N_{5}}{D_{2}}$

Where

$\mathrm{N}_{5}=\mathrm{p}_{02}\left(1-\mathrm{p}_{11.4}\right)$ and $\mathrm{D}_{2}$ is already specified

\section{COST-BENEFIT ANALYSIS}

The profit incurred to the system model in steady state can be obtained as:

$P=K_{0} A_{0}-K_{1} B_{0}^{H}-K_{2} B_{0}^{S}-K_{3} N H R_{0}-K_{4} N S U_{0}$

where

$\mathrm{K}_{0}=$ Revenue per unit up-time of the system

$\mathrm{K}_{1}=$ Cost per unit time for which server is busy due to hardware repair

$\mathrm{K}_{2}=$ Cost per unit time for which server is busy due to software up-gradation

$\mathrm{K}_{3}=$ Cost per unit repair of the failed hardware

$\mathrm{K}_{4}=$ Cost per unit up-gradation of the failed software and $A_{0}, B_{0}^{H}, B_{0}^{S}, N H R_{0}, N S U_{0}$ are already defined.

\section{PARTICULAR CASES}

Suppose $g(t)=a e^{-a t}$ and $f(t)=\theta e^{-\theta t}$

We can obtain the following results:

$\operatorname{MTSF}\left(\mathrm{T}_{0}\right)=\frac{N_{1}}{D_{1}}$

Availability $\left(\mathrm{A}_{0}\right)=\frac{N_{2}}{D_{2}}$

Busy period due to hardware failure $\left(B_{0}^{H}\right)=\frac{N_{3}^{H}}{D_{2}}$

Busy period due to software failure $\left(B_{0}^{S}\right)=\frac{N_{3}^{S}}{D_{2}}$

Expected number of repair at hardware failure $\left(N H R_{0}\right)=\frac{N_{4}}{D_{2}}$

Expected number of up-gradation at software failure $\left(N S U_{0}\right)=\frac{N_{5}}{D_{2}}$

Where

$$
\begin{aligned}
& N_{1}=\frac{2 a \lambda_{1}+b \lambda_{2}+\alpha}{\left(a \lambda_{1}+b \lambda_{2}\right)\left(a \lambda_{1}+b \lambda_{2}+\alpha\right)} \\
& D_{1}=\frac{\left(a \lambda_{1}+b \lambda_{2}\right)\left(a \lambda_{1}+b \lambda_{2}+\alpha\right)-a \lambda_{1} \alpha}{\left(a \lambda_{1}+b \lambda_{2}\right)\left(a \lambda_{1}+b \lambda_{2}+\alpha\right)} \\
& N_{2}=\frac{1}{a \lambda_{1}+b \lambda_{2}} \\
& D_{2}=\frac{\left(a \lambda_{1}+b \lambda_{2}+\alpha\right)\left(\theta a \lambda_{1}+\alpha b \lambda_{2}\right)+\theta \alpha\left(b \lambda_{2}+\alpha\right)}{\theta \alpha\left(a \lambda_{1}+b \lambda_{2}\right)\left(a \lambda_{1}+b \lambda_{2}+\alpha\right)}
\end{aligned}
$$

$$
\begin{aligned}
N_{3}^{H}= & \frac{a \lambda_{1}}{\alpha\left(a \lambda_{1}+b \lambda_{2}\right)} \\
& N_{3}^{S}=\frac{b \lambda_{2}}{\theta\left(a \lambda_{1}+b \lambda_{2}\right)}
\end{aligned}
$$




$$
\begin{aligned}
& N_{4}=\frac{a \lambda_{1}\left(b \lambda_{2}+\alpha\right)}{\left(a \lambda_{1}+b \lambda_{2}\right)\left(a \lambda_{1}+b \lambda_{2}+\alpha\right)} \\
& N_{5}=\frac{b \lambda_{2}\left(b \lambda_{2}+\alpha\right)}{\left(a \lambda_{1}+b \lambda_{2}\right)\left(a \lambda_{1}+b \lambda_{2}+\alpha\right)}
\end{aligned}
$$

\section{CONCLUSION}

The effect of various parameters on performance measures of computer system model has been observed for a particular case as shown in figures 2, 3, and 4. It is analyzed that mean time to system failure (MTSF), availability and profit function go on decreasing with the increase of failure rates $\left(\lambda_{1}\right.$ and $\left.\lambda_{2}\right)$ while their values increase with the increase of hardware repair rate $(\alpha)$ and software up-gradation rate $(\theta)$ provided chances of hardware failure rate are more than that of software failure $(a>b)$. However, the effect software failure rate is more on these measures. It is interesting to note that MTSF and availability decline in case software failure chances are high whereas system becomes more profitable may because of less cost for software up-gradation.

Hence, a computer system in which hardware redundancy is provided in cold standby can be made more profitable and reliable to use either by operating the software carefully or by increasing hardware repair rate and software up-gradation rate giving less cost for software up-gradation.

\section{ACKNOWLEDGEMENT}

The authors are grateful to the experts who have contributed towards development of the paper.

\section{REFERENCES}

[1] Anand, Jyoti and Malik, S.C. (2012): Analysis of a Computer System with Arbitrary Distributions for H/W and S/W Replacement Time and Priority to Repair Activities of $\mathrm{H} / \mathrm{W}$ over Replacement of the $\mathrm{S} / \mathrm{W}$, International Journal of Systems Assurance Engineering and Management, Vol.3 (3), pp. 230-236.

[2] Cao, Jinhua and Wu, Yan Hong (1989): Reliability of two-unit cold standby system with replaceable repair facility. Microelectronics \& Reliability, Vol. 29(2), pp. 145-150.

[3] Kumar, Ashish; Anand, Jyoti and Malik, S.C. (2013): Stochastic Modeling of a Computer System with Priority to Up-gradation of Software over Hardware Repair Activities. International Journal of Agricultural and Statistical Sciences, Vol. 9(1), pp. 117-126.

[4] Kumar, Jitender; Kadyan, Mukender Singh and Malik, Suresh Chander (2012): Cost-analysis of a two-unit cold standby system subject to degradation, inspection and priority. Maintenance and Reliability, Vol. 14(4), pp. 278-283.

[5] Lam, Y.F. (1997): A maintenance model for two-unit redundant system. Microelectronics \& Reliability, Vol. 37(3), pp. 497-504.

[6] Malik, S.C. and Anand, Jyoti (2010): Reliability and economic analysis of a computer system with independent hardware and software failures. Bulletin of Pure and Applied Sciences, Vol. 29E(01), pp.141-153.

[7] Yadavalli, V.S.S., Chanderasekhar and Natarajan, R. (2004): A study on two-unit standby system with Erlangian repair time. Asia-Pacific Journal of Operational Research, Vol. 21(3), pp. 271-277.

\section{State Transition Diagram}

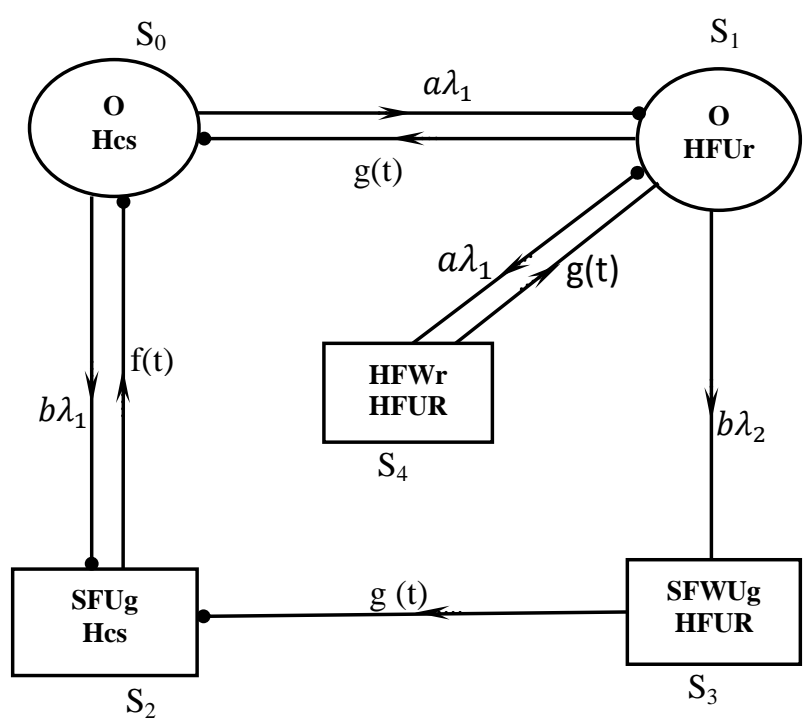

Up-State

Failed State

Regenerative Point

Fig. 1 

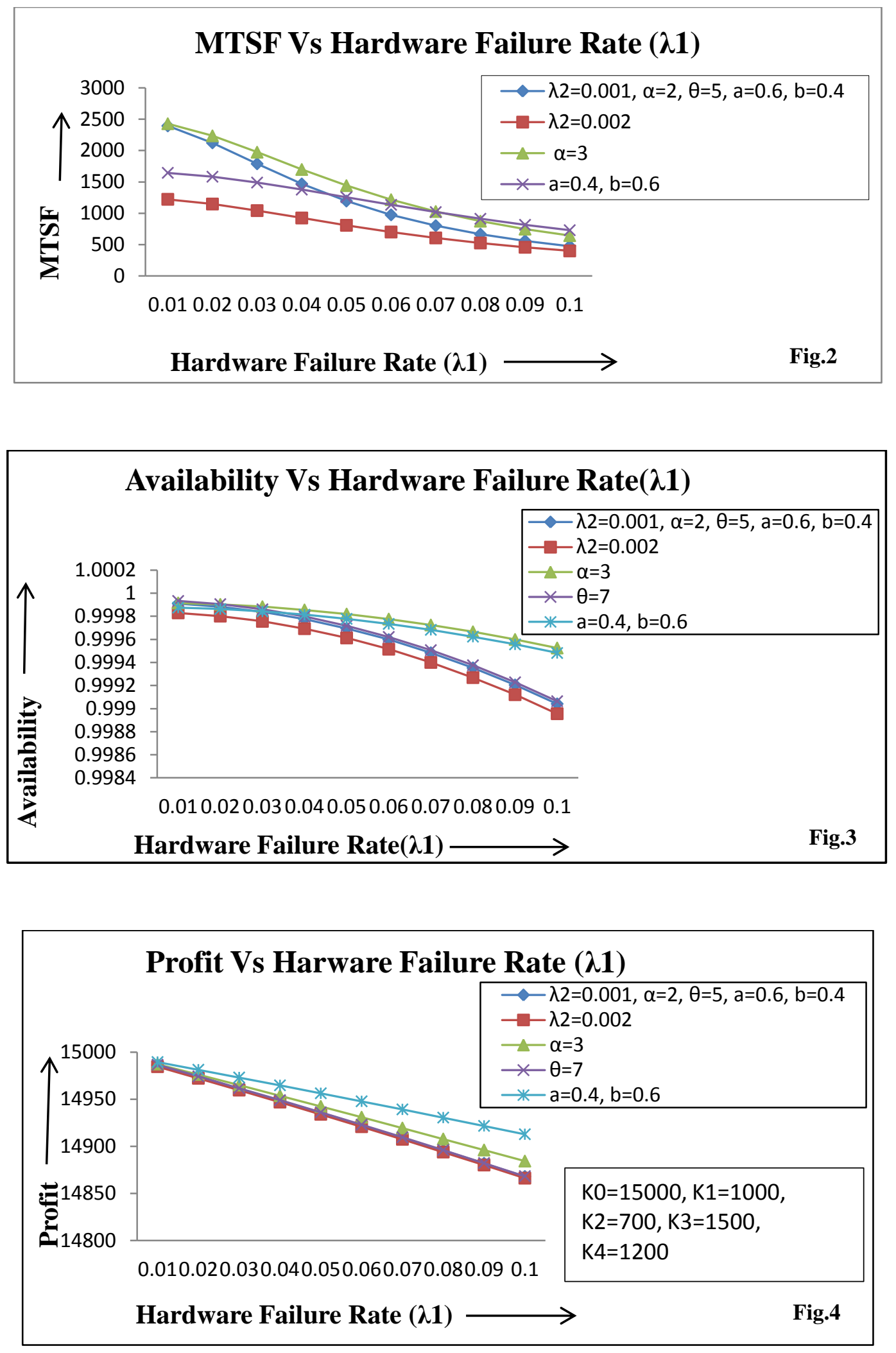